\title{
The Application of Chinese Traditional Qiang Embroidery Patterns in Decorative Design
}

\author{
Yang Mou \\ Yibin Vocational and Technical College \\ Yibin, China
}

\begin{abstract}
Chinese traditional Qiang embroidery patterns have a long history and a deep cultural deposit and concentrate the essence of Chinese art. Our nation is in the stage of rapid development of information, so the rapid influx and impact of foreign culture makes decoration art gradually lose the national character. With the increasing demands on design connotation from people, modern decorative design should pay more attention to traditional cultures. Fusing Chinese traditional regional embroidery patterns into decorative design to add design skills can manifest national features and make decorative design more traditional.
\end{abstract}

Keywords-Qiang embroidery patterns; Qiang embroidery connotation; decorative design; application

\section{INTRODUCTION}

At present, there are various domestic research achievements about traditional regional decorative patterns. But few of them are combined with modern decorative design. Most of the cases are researches of the application in traditional architecture. There are few cases of regional patterns applied in modern decorative design, so such design has broad research space.

Our ancestors created pottery patterns, lacquer patterns, porcelain patterns, fabric patterns and decorative patterns in architecture from life. Chinese traditional patterns are rich in theme and contents, most of which have good blessings and expectations with deep meanings. Chinese traditional patterns have been already embodied in dwellings. Now, by researching and exploring on them, we can learn about life and customs of a nation, date back to the essence of Chinese culture, comprehend the connotation of Chineseness and take in advanced ideas and means to apply Chinese traditional patterns into the decorative design of walls, grounds, ceilings, drapery fabrics and layout and create Chinese distinctive decorative design culture.

In various Chinese traditional patterns, the Qiang embroidery patterns have unique artistic beauty and cultural background, which makes it splendid in the history of the Chinese traditional culture. Recent years, with the rapid development of domestic decorative industry and continuous appearance of new materials, new design and new technology, foreign design thoughts and concept strike those of China. Domestic decoration design chase and imitate that of western blindly make s our national art gradually lose its personality. But there are many international design that applied Chinese elements, some designers even consider that design without Chinese elements is not noble. Chinese traditional Qiang embroidery patterns have a profound cultural background. If they are applied to the design of the decoration, they can reflect national culture characteristics, show national features better and make the decoration design have deep cultural connotation and characteristics. Combining Qiang embroidery patterns with modern life style and aesthetic demands, fusing traditional regional decoration into modern space by new technology will have better decorative effects.

\section{FEATURES AND CONNOTATION OF TRADITIONAL QIANG EMBROIDERY PATTERNS}

Every nation has its preference on beauty. It embodies its unique aesthetic habits and implies rich cultural information. Qiang ethnic minority has a long history, which can be dated back to XI Qiang moved from the northwest area. People of the nation have their own wisdom and worship beauty and live in the upper reaches of the Minjiang River. Because of the close geographical conditions, they still keep unique national characters. Take the Qiang embroidery of Qiang ethnic minority as an example, the Qiang embroidery is an important part of its national art. It comes from the ancient Qiang culture and circulates up to now after thousands of years' sedimentation. It reflects special social environment and unique aesthetic consciousness of the ethnic. For the ethnic without its own characters, the Qiang embroidery patterns contain historical and cultural connotation behind the ethnic, record its development process and pursuits of people here for better things and bear cultural ideology, art concept and life attitude of the ethnic. The Qiang embroidery patterns are various in sorts, such as geometric patterns, plant patterns, animal patterns and natural objects patterns, all of which have deep cultural implication.

\section{A. Reflection of the Qiang Embroidery on the Living Environment}

Because of the migration of Qiang ethnic minority, they finally settled in the high mountains and great rivers. In the Qiang embroidery, Qiang people recreated arts through exaggeration, deformation, refining and fusion, which 
embodied customs and environment and extended Qiang people's aesthetic concept that worship freedom and don't be restrained. This is also one of the main aesthetic tones of Qiang embroidery patterns. In addition, because they lived in the mountains, they are called "the nation on the cloud", so there are clouds deformation patterns in many Qiang embroidery patterns, meaning auspices. The Qiang embroidery patterns generalized animal and plants in nature by geometric design and displayed their appreciation to the beauty of nature.

\section{B. Reflection of the Qiang Embroidery on Belief}

The Qiang embroidery patterns contain the beauty of primitive simplicity, customs of worshiping deities and religious belief. They also have the beauty of nature and harmony. The Qiang embroidery patterns interest to us rich visual esthetics in the form of a unique aesthetic feeling and aesthetic temperament. Applying these traditional decorative patterns to the decorative design can express strong nation breath and emotion. Making decorative art fuse with the essence of traditional regional patterns and inheriting and creating national characters in decoration have profound meaning in Chinese architecture decoration. For example, the Qiang ethnic minority worship sheep, so they make the patterns like a sheep to express their respect with the hope of bless and shelter. There are also a lot of worship cultures in the Qiang embroidery patterns. For example, a series of patterns derived from fire and sun such as fire pattern, flame figure and brazier flowers show Qiang people's worship to deities and religious belief, which have a strong national characters and artistic appeal.

\section{Reflection of the Qiang Embroidery on Implied Meaning}

There is a theme expressing the yearning and longing for a better life in the Qiang embroidery patterns. For example, Rhododendron Flower symbols love in Qiang ethnic minority. As a classic pattern, it means love and happy marriage. The Han embroidery patterns also influenced that of Qiang greatly. For example, Pomegranate pattern means sons and grandsons pervading the hall; the butterfly pattern means happiness and auspices; the lion pattern means mascot; Chrysanthemum pattern means longevity and fruits pattern means harvest. A lot of lucky patterns are used by combining composition in the Qiang embroidery patterns, such as the harmony between fish and water and harmony among flowers. The reflection of patterns expresses people's praise of good things and yearning for better life.

\section{APPLICATION OF TRADITIONAL QIANG EMBROIDERY PATTERNS IN DECORATIVE DESIGN}

In ancient times, there are beautiful patterns on girder, column, sunk panel, ceiling, doors and windows and utensils. From this we can find that the Chinese traditional patterns have deeply rooted in the space of Chinese decorative design. Our modern life style and habits are formed on the basic of Chinese traditional patterns. While in order to meet the aesthetic need of clients, decorative designers pursue western design styles but ignore our traditional cultures. Mining and refining distinctive element features and symbols of traditional regional patterns under certain guidance or applying them into decoration indirectly can manifest flawlessness in Chinese traditional culture.

Traditional architecture decorative patterns are embossment, hollow and colored drawing on two-dimensional surface. Modeling characteristic of this decoration is not prominent and patterns connotation can't be displayed very well. However, modern design has three-dimensional form design beside the plane. Especially in decorative design of architectures, designers pay more attention to scrutiny and creativity in three-dimensional space so the finished work isn't displayed by planes but different shapes and states seeing from different views. Therefore, designers must have ability of spatial imagination and stereo thinking. So, when thinking how to display creative of traditional Qiang embroidery patterns, designers should also think how to play the composition and stereoscopic effect of the patterns in space design but still keep inherent characteristics of patterns. Designers should notice the restriction of concrete interior building structure, spatial scale, construction technology and materials technology in practice and consider the achieving possibility of the shape comprehensively, which adds difficulty to creative and application of Qiang embroidery in decorative design. If designers can design carefully and make it come true, the decorative design can surely meet the need of modern design demands and add charming to traditional Qiang embroidery patterns.

\section{A. Application in Decorative Modeling}

The Qiang embroidery patterns are rich in colors and wide in contents with strong decorativeness. Flowers, fish, birds and animals in nature are all patterns of Qiang embroidery. Designers can summarize modeling features of Qiang embroidery to simplify the animal shapes and then apply them into the decoration of wall and door frame. In addition, the shape "wan" can be used in wainscot. Cloud patterns can decorate incase, door plank, screen and the back of chairs. In modern decorative design, concision and sprightliness are the mainstream. Ceiling usually use plasterboard or grid, so the geometry patterns and plant patterns in modern decorative design add funny and connotation to the shape of ceiling. These patterns are expressed by refactoring technique and conform to the modern's aesthetic temperament and interest and increase the design connotation.

\section{B. Application in Decorative Materials}

With the rapid development of decorative industry, new materials emerge constantly. Because of the improvement of decorative materials, indoor decoration has a variety of materials to choose, such as stone, wood, ceramics, amberina and plaster products. Different decorative materials have different decorative styles and effects. For example, designers can apply Qiang embroidery patterns to ceramic bricks, and Laying on the ground or linear to decorate the indoor ground. It also can be used in modern perspex sheet and tempered glass by colored drawing and carving to divide space and make furniture. Using continuous clouds patterns and plat patterns in timber, stone and plaster products can express traditional patterns by new colors and ways and root gorgeous color and careful printing into modern life. 


\section{Application in Decorative Colors}

The Qiang embroidery is rich in colors. Designers can apply these colors to decorative design to combine national colors with modern design. For example, the first is burlywood color. It comes from the color of trees in Qiang embroidery patterns, which embodies original ecological ethnic style. Designer can highlight this color particularly to give people a feeling of returning to nature. The second is cuckoo red. Rhododendron is holy in Qiang ethnic minority. This color represents joy and auspices and can be used as soft outfit bright color. The third is white. It is used as the underpainting in Qiang embroidery. Chinese people worship elegance in architecture. The color white is plain and gives people a sense of tranquility. It can be used as transition color in indoor space, doors, windows and partition wall. The fourth is the color bright yellow. It displays the activeness in national elements and makes people feel vivacious. The fifth is light green. It is the favorite of refined scholars and can be used in wall and soft outfit because of its long feeling. The sixth is light grey. It is mysterious meaningful so it can be used in the decoration of furniture.

\section{Application in Soft Outfit Design}

Recent years, people's concept of valuing adornment while lighting decoration has been deepened, and people's demands on decorative design. People become keen on soft outfit design. It includes decorative fabric, hanging drop, furnishings and Curtain cloth art. It can divide space effectively and make confluent atmosphere to add administrative levels feeling of the space. In soft outfit design, designers can introduce plant patterns, patterns of character Wan and the patterns of phoenix in Qiang embroidery. For example, designers can adopt these traditional patterns in soft outfit fabrics such as curtain, bedding articles, cloth sofa, cushion, carpet and textile wall covering to add beauty and atmosphere to indoor space.

\section{CONCLUSION}

The author researched and analyzed creative skills and culture connotation of traditional Chinese regional decorative patterns. The essence of the application of traditional Chinese regional decorative patterns lies in building decorative space environment and expressing people's best wishes by patterns. As a art design of traditional handicraft industry era, the Qiang embroidery patterns have historical limitations undoubtedly. However, if applying them into modern decorative design, they must be processed artificially to cater modern decorative design concept and developing trend and enrich them new functions and shapes. Applying materials implied good meanings into modern decorative design reasonably. In pattern of manifestation, traditional Qiang embroidery patterns are various in shapes and styles. They have intact form beauty and they deserve our study, research and popularization no matter in composition or organization, so they can serve modern decorative design. Understanding the connotation of traditional Qiang embroidery patterns fully and innovating and applying them through modern design concepts can add more humanistic connotation to modern decorative design. In practice, designers should make thought clear, apply traditional Qiang embroidery patterns which are strongly beautiful in form and brief and lively in shape into decoration directly. While for those complicated patterns, they should simplify and change them, or use them indirectly through simplifying, abstract, dividing and recombination. In the rapid developing stage, design should follow people first and meet the need of diversification and sustainable development. Economy, scientificity, practicability and traditional aesthetic should be reflected on architecture decorative design.

Application and innovation of Chinese traditional Qiang embroidery patterns should conform to the modern social culture background and modern design concept and combine with modern design expression. Constantly widening application of Chinese traditional Qiang embroidery patterns in modern decorative design to make Chinese traditional patterns more adaptable and more close to people's life and make Chinese traditional culture fuse into modern life styles in the form of natural appearance.

\section{REFERENCES}

[1] Qin Meiyu, Li Zhao. A research on the Qiang cultural ecology, morphology and evolution path $[\mathrm{J}]$. Journal of southwest university for nationalities, Aug, 2013:Page 47-49.

[2] Liu Tinger, Application of Chinese traditional auspicious patterns in modern home decoration [J] Art Science and Technology, May 26, 2013 , Page 24.1.

[3] Lu Yuanding, Interior design and decoration[M]. Beijing: Sanlian publishing house, 2008.

[4] Lou Qingxi, Chinese traditional architectural decoration[M]. Beijing: China building industry press, 1999. 